\title{
Pengaruh Brand Image dan Persepsi Harga Terhadap Kualitas Pelayanan dan Kepuasan Pelanggan (Studi pada Pelanggan Datsun Nissan Martadinata)
}

\author{
Oscar Marco Sanny Junior \\ William A. Areros \\ Riane J. Pio \\ Jurusan Manajemen Perusahaan, Program Studi Pengelolaan Sumberdaya Pembangunan \\ Fakultas Pasca Sarjana, Universitas Sam Ratulangi \\ oscarmarcosjr@gmail.com
}

\begin{abstract}
The immediate objectives of this research is to determined the effect of (1) Brand Image towards Service Quality on Datsun Nissan Martadinata customers, (2) Brand Image towards Customer Satisfaction on Datsun Nissan Martadinata customers, (3) Price Perception of Service Quality on Datsun Nissan Martadinata customers, (4) Price Perception of Customer Satisfaction on Datsun Nissan Martadinata customers, and (5) Service Quality towards Customer Satisfaction on Datsun Nissan Martadinata customers. The quantitative research is adapted as the method in this study and used questionnaire as the reflection of its method. Datsun buyers at Nissan Martadinata Manado are used as the population and Datsun customers are used as the samples. The questionnaires will be distributed with purposive sampling method. This study uses SmartPLS software to assist the Partial Least Square (PLS) analysis. The study resulted in 3 hypotheses were rejected from 5 hypotheses.
\end{abstract}

Keywords: Brand Image, Price Perception, Service Quality, and Customer Satisfaction

\section{Pendahuluan}

Tidak bisa dipungkiri bawah saat ini kendaraan roda empat sudah menjadi sebuah kebutuhan umum bagi masyarakat yang mempunyai dana untuk membelinya. Berdasar-kan data Gabungan Industri Kendaraan Bermotor Indonesia (Gaikindo), penjualan wholesales kendaraan roda empat sepanjang 2017 lalu mencapai 1.079.308 unit. Pencapaian ini meleset dari target penjualan yang sudah ditetapkan Gaikindo sebanyak 1,1 juta unit. Meski begitu, angkanya masih lebih baik dibandingkan tahun 2016 yang mencapai 1.062 .716 unit.
Dengan semakin ketatnya persaingan dalam bidang otomotif khususnya kendaran roda empat, maka pelaku bisnis tentunya harus mampu bersaing agar tidak ditinggalkan oleh pelanggan. Salah satu hal yang dapat dilakukan oleh sebuah perusahaan untuk mampu bertahan dalam ketatnya persaingan pasar adalah dengan cara memenuhi kepuasan pelanggan. Kepuasan pelanggan sendiri adalah tingkat perasaan pelanggan setelah membandingkan antara apa yang dia terima dan harapannya (Umar, 2005). Seorang pelanggan, jika merasa puas dengan nilai yang diberikan oleh produk atau jasa, 
sangat besar kemungkinannya menjadi pelanggan dalam waktu yang lama.

Melihat uraian tersebut, maka perusahaan harus memiliki rancangan strategi yang tepat dalam mencapai tujuan memuaskan pelanggan. Dengan persaingan yang semakin ketat, dimana semakin banyak produsen yang terlibat dalam pemenuhan kebutuhan dan keinginan pelanggan, bisnis otomotif harus memiliki brand image yang kuat serta menempatkan orientasi kepada harga dan kualitas pelayanan sebagai tujuan.

Setiadi (2003) berpendapat: Brand Image mengacu pada skema memori akan sebuah merek, yang berisikan interpretasi pelanggan atas atribut, kelebihan, penggunaan, situasi, para pengguna, dan karakteristik pemasar dan/atau karakteristik pembuat dari produk/merek tersebut. Brand Image adalah apa yang pelanggan pikirkan dan rasakan ketika mendengar atau melihat nama suatu merek. Datsun boleh dibilang merupakan pendatang baru di Indonesia karena secara resmi hadir sejak enam tahun lalu, tepatnya sejak 2012. Datsun adalah merek mobil yang dimiliki oleh Nissan Motor Company. Datsun digunakan sebagai merek dari kendaraan Nissan yang diekspor tahun 1958 sampai 1986. Pada tahun 2012, Datsun diluncurkan kembali sebagai merek mobil murah Nissan.

Kemudian ada persepsi harga yang juga merupakan salah satu faktor yang sangat penting dalam mempengaruhi keputusan pembelian pelanggan. Harga yang rendah atau harga yang terjangkau menjadi pemicu untuk meningkatkan kinerja pemasaran (Ferdinand, 2002). Persepsi harga mempengaruhi keputusan pelanggan dalam pengambilan keputusan untuk pembelian suatu produk.

Kualitas pelayanan juga merupakan faktor yang penting dalam pemasaran. Menurut Suwithi (1999) Kualitas pelayanan adalah mutu dari pelayanan yang diberikan kepada pelanggan, baik pelanggan internal maupun pelanggan eksternal berdasarkan standar prosedur pelayanan.

Seperti diketahui saat ini Datsun di Indonesia memiliki tiga model. Dua dari tiga model tersebut bermain di pasar mobil murah ramah lingkungan (LCGC). Hanya model terbaru Datsun Cross yang dibuat tidak seperti konsep LCGC 2 model sebelumnya. Istilah Low Cost Green Car (LCGC) sangat populer di dunia otomotif Indonesia. Mobil ini harganya sangat terjangkau karena keringanan pajak. Selain itu, hemat bahan bakar, tingkat polusi rendah dan diproduksi di dalam negeri menjadi konsep dasarnya.

Memahami faktor-faktor yang mempengaruhi kepuasan pelanggan hendaknya juga dilakukan oleh Nissan Martadinata, sebab dalam perkembangannya mereka mengalami permasalahan dengan penurunan yang tajam pada jumlah pelanggan. Berdasarkan data Gaikindo, sepanjang tahun 2017 (hingga September 2017) pasokan ke diler merek yang berada di bawah bendera PT Nissan Motor Indonesia ini anjlok 205,62\% dibandingkan sembilan bulan pertama tahun 2016, atau dari 23.909 unit menjadi 7.823 unit. Merek ini hanya kebagian 
4,35\% pelanggan LCGC. Kehadiran Toyota Calya, dan Daihatsu Sigra diduga menjadi penyebab melemahnya penjualan Datsun.

Peniliti memilih Nissan Martadinata sebagai objek penelitian dikarenakan menurut peneliti Nissan Martadinata ingin memperbaiki diri untuk menjadi lebih baik dibandingkan dengan pesaing-pesaingnya, dimana ada terjadinya penurunan penjualan Datsun Nissan Martadinata sejak seperti yang terlihat pada bar chart dibawah ini.

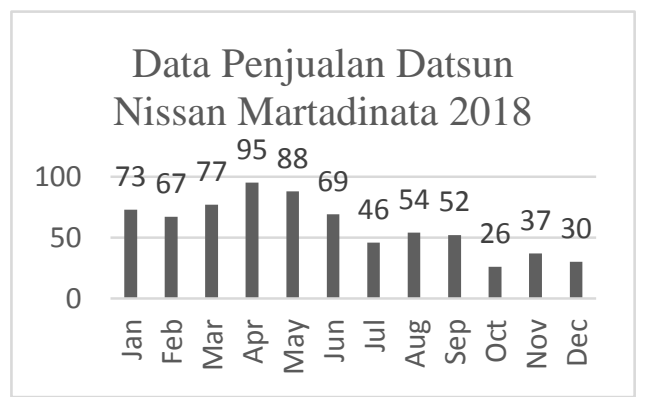

\section{Brand Image}

Pengertian brand image menurut Tjiptono (2005) adalah deskripsi tentang asosiasi dan keyakinan pelanggan terhadap merek tertentu. Citra merek itu sendiri memiliki arti kepada suatu pencitraan yang sama terhadap sebuah merek.

Menurut Keller (2000) setiap produk yang terjual dipasaran memiiki citra tersendiri di mata pelanggannya yang sengaja diciptakan oleh pemasar untuk membedakannya dari para pesaing. Citra merek dianggap sebagai jenis asumsi yang muncul dalam benak pelanggan ketika mengingat suatu merek tertentu. Asumsi tersebut secara sederhana dapat muncul dalam bentuk pemikiran atau citra tertentu yang dikaitkan dengan suatu merek, sama halnya ketika seseorang berpikir tentang orang lain. Menurut Kotler dan Armstrong (2001) yang mengintrepetasi adalah pelanggan dan yang diintrepetasikan adalah informasi. Informasi citra dapat dilihat dari logo atau simbol yang digunakan oleh perusahaan untuk mewakili produknya. Dimana simbol dan logo ini bukan hanya sebagai pembeda dari pesaing sejenis namun juga dapat merefleksikan mutu dan visi misi perusahaan tersebut.

Paul dan Olson (2000) menyatakan bahwa persepsi harga berkaitan dengan bagaimana informasi harga dipahami seluruhnya oleh pelanggan dan memberikan makna yang dalam bagi mereka. Dari sudut pandang produsen, harga merupakan komponen yang berpengaruh langsung terhadap laba perusahaan dalam artian merupakan pendapatan. Sementara itu, dari sudut pandang pelanggan harga sering kali digunakan sebagai indikator nilai bilamana harga tersebut dihubungkan dengan manfaat yang dirasakan atas suatu produk atau dalam arti kata harga merupakan pengorbanan bagi pelanggan dalam mendapatkan suatu produk. Namun secara sederhana, harga dapat diartikan sebagai sejumlah uang (satuan moneter) dan atau aspek lain (non-moneter) yang mengandung kegunaan tertentu yang diperlukan untuk mendapatkan suatu produk/jasa.

Banyak aspek yang menjadi pertimbangan seorang pelanggan untuk memilih salah satu tempat yang menjual produk yang diinginkannya. Tentunya selain aspek harga dan ketersediaan barang, 
hal lain yang dicari pelanggan adalah kualitas pelayanan. Menurut Sugiarto (2002), suatu kualitas disebut baik apabila penyedia jasa memberikan pelayanan yang melebihi harapan pelanggan. Kualitas tersebut dinilai baik apabila penyedia jasa memberikan pelayanan setara harapan pelanggan. Jika nasabah atau pelanggan mendapatkan pelayanan lebih rendah dari harapannya maka kualitas jasa tersebut di nilai jelek. Pencapaian kepuasan pelanggan memerlukan keseimbangan antara kebutuhan dan keinginan dan apa yang diberikan.

Menurut Kotler (2000), kualitas pelayanan merupakan totalitas dari bentuk karakteristik barang dan jasa yang menunjukkan kemampuannya untuk memuaskan kebutuhan pelanggan, baik yang nampak jelas maupun yang tersembunyi. Bagi perusahaan yang bergerak di sektor jasa, pemberian pelayanan yang berkualitas pada pelanggan merupakan hal mutlak yang harus dilakukan apabila perusahaan ingin mencapai keberhasilan.

Adapun manfaat pelayanan terhadap pelanggan menurut Blumberg (1999), yaitu Pelayanan memperpanjang dasar hidup suatu produk yaitu pelayanan bukan saja bagian yang penting dari suatu produk, tapi juga memberikan pendapat dan keuntungan yang lebih besar melalui dasar hidup suatu produk dan Pelayanan dapat menambah nilai suatu produk yaitu adalah pelayanan dapat menambah nilai suatu produk secara langsung.
Menurut Gerson (2002) kepuasan pelanggan adalah persepsi pelanggan bahwa harapan telah terpenuhi atau terlampaui, jika pelanggan berharap barang tersebut akan befungsi dengan baik. Jika tidak pelanggan akan kecewa. Maka perusahaan harus menemukan cara untuk mengatasi masalah tersebut sehingga pelanggan bisa menjadi puas. Pelanggan yang puas akan melakukan bisnis lebih banyak dan lebih sering dengan suatu perusahaan, sehingga keuntungan perusahaan semakin besar.

\section{Kepuasan pelanggan adalah} merupakan persepsi pelanggan terhadap produk atau jasa yang telah memenuhi harapannya (Irawan, 2007). Pelanggan tidak akan puas apabila pelanggan mempunyai persepsi bahwa harapannya belum terpenuhi dan sebaliknya pelanggan akan puas apabila persepsinya sama atau lebih dari yang diharapkan. Sedangkan menurut Lovelock dan Wright (2005), kepuasan pelanggan adalah keadaan emosional, reaksi pasca-pembelian mereka dapat berupa kemarahan, ketidakpuasan, kejengkelan, netralitas, kegembiraan atau kesenangan.

\section{Metode Penelitian}

Penulis menggunakan metode penelitan kuantitatif pada penelitian yang dilakukan di Nissan Martadinata dan terletak di Kelurahan Tikala, Paal Dua, Jl. R.E. Martadinata No.64, Dendengan Luar, Tikala, Manado, Sulawesi Utara. Populasi dari penelitian ini adalah pembeli Datsun di Nissan Martadinata Manado dengan jumlah 
populasi 60 orang. Teknik yang digunakan dalam menentukan sampel adalah rumus slovin.

$$
\mathrm{n}=\frac{N}{1+N(e)^{2}}
$$

Dimana sampel yang didapat dengan menggunakan rumus tersebut sebanyak 53 orang. Teknik pengumpulan data menggunakan bantuan kuesioner. Penelitian ini akan menggunakan analisis Partial Least Square (PLS) dengan bantuan software SmartPLS untuk mengetahui pengaruh antara variabel brand image dengan kepuasan pelanggan, variabel brand image dengan kualitas pelayanan, variabel persepsi harga dengan kualitas pelayanan, variabel persepsi harga dengan kepuasan pelanggan, serta variabel kualitas pelayanan dengan kepuasan pelanggan. Langkah-langkah yang akan ditempuh dalam analisis data setelah kuesioner ditabulasi adalah: 1) Membuat tabel distribusi variabel brand image. 2) Membuat tabel distribusi variabel persepsi harga. 3) Membuat tabel distribusi variabel kualitas pelayanan. 4) Membuat tabel distribusi variabel kepuasan pelanggan. 5) Mengkonstruksi diagram path. 6) Proses komputasi.

\section{Hasil Penelitian}

Hasil yang didapatkan sesuai analisis uji validitas dengan menggunakan smartPLS menyatakan bahwa semua pernyataan pada kuesioner diketahui bahwa variabel X1 (Brand Image), X2 (Persepsi Harga), Y1 (Kualitas Pelayanan), dan Y2 (Kepuasan Pelanggan) Tabel dibawah ini memperlihatkan bahwa tidak ada nilai yang lebih besar dari angka paling kanan setiap barisnya. Dengan demikian dapat disimpulkan bahwa semua item telah memenuhi validitas.

\begin{tabular}{|c|c|c|c|c|}
\hline & $\mathrm{X} 1$ & $\mathrm{X} 2$ & $\mathrm{Y} 1$ & $\mathrm{Y} 2$ \\
\hline $\mathrm{X} 1$ & 0.813 & & & \\
\hline $\mathrm{X} 2$ & 0.413 & 0.854 & & \\
\hline $\mathrm{Y} 1$ & 0.330 & 0.778 & 0.882 & \\
\hline $\mathrm{Y} 2$ & 0.661 & 0.573 & 0.365 & 0.844 \\
\hline
\end{tabular}

Kemudian untuk uji realibilitas, nilai Alpha Cronbach keempat variabel telah melebihi nilai 0.7 , dengan demikian dapat disimpulkan bahwa instrumen telah memenuhi persyaratan valid dan reliabel, sehingga data yang diperoleh dari kuesioner dapat digunakan untuk analisis data pada tahap selanjutnya.

Pengaruh Brand Image (X1) terhadap Kualitas Pelayanan (Y1), diperoleh koefisien struktural sebesar 0.158 dan $\mathrm{P}$-value $<0.423$. Karena $\mathrm{P}$-value $<0.05$, mengindikasikan bahwa tidak signifikannya pengaruh antara Brand Image (X1) terhadap Kualitas Pelayanan (Y1). Artinya semakin tingginya Brand Image (X1), tidak akan mempengaruhi tinggi rendahnya Kualitas Pelayanan (Y1). Dengan demikian, hipotesis 1 penelitian ini ditolak. Hasil penelitian ini tidak sejalan dengan teori menurut Kotler dan Keller (2012) yang mengatakan Brand Image menggambarkan sifat ekstrinsik dari suatu produk atau jasa termasuk cara dimana merek berusaha memenuhi kebutuhan psikologis atau sosial pelanggan. Dalam penelitian ini, variabel Brand Image belum 
bisa memenuhi kebutuhan psikologis atau sosial dari pelanggan dalam aspek kualitas pelayanan.

Pengaruh Brand Image (X1) terhadap Kepuasan Pelanggan (Y2), diperoleh koefisien struktural sebesar 0.044 dan P-value <0.701. Karena Pvalue $<0.05$, mengindikasikan bahwa tidak signifikannya pengaruh antara Brand Image (X1) terhadap Kepuasan Pelanggan (Y2). Artinya semakin tingginya Brand Image (X1), tidak akan mempengaruhi tinggi rendahnya Kepuasan Pelanggan (Y2). Dengan demikian, hipotesis 2 penelitian ini ditolak. Hasil ini didukung oleh teori dari Marshall et al. (1999) yang mengatakan bahwa image tidak dapat diukur dan dievaluasi, evaluasi image harus mencakup evaluasi persepsi pelanggan terhadap image dan merek barang, titik inilah yang melibatkan pentingnya citra merek untuk kepuasan pelanggan.

\section{Pengaruh Persepsi Harga (X2)} terhadap Kualitas Pelayanan (Y1), diperoleh koefisien struktural sebesar 0.261 dan P-value $<0.204$. Karena P-value $<0.05$, mengindikasikan bahwa tidak signifikannya pengaruh antara Persepsi Harga (X2) terhadap Kualitas Pelayanan (Y1). Artinya semakin tingginya Persepsi Harga (X2), tidak akan mempengaruhi tinggi rendahnya Kualitas Pelayanan (Y1). Dengan demikian, hipotesis 3 penelitian ini ditolak. Peran harga penting untuk ekonomi. Harga dapat memengaruhi tingkat upah, sewa, laba, dan bunga. Harga adalah pengatur dasar dalam sistem ekonomi karena harga mempengaruhi alokasi faktor-faktor produksi. Kemudian bagi konsumen harga sangat sensitif meskipun memiliki pertimbangan merek, gambar, lokasi, layanan, nilai dan kualitas produk. Seringkali harga mahal diperkirakan berkualitas tinggi dan harga murah dianggap produk berkualitas rendah.

Pengaruh Persepsi Harga (X2) terhadap Kepuasan Pelanggan (Y2), diperoleh koefisien struktural sebesar 0.361 dan P-value <0.001. Karena P-value $<0.05$, mengindikasikan bahwa adanya pengaruh signifikan antara Persepsi Harga (X2) terhadap Kepuasan Pelanggan (Y2). Artinya semakin tingginya Persepsi Harga (X2), akan mempengaruhi semakin tingginya Kepuasan Pelanggan (Y2). Dengan demikian, hipotesis 4 penelitian ini diterima. Hasil ini didukung oleh teori Tjiptono (2002) yang mengatakan apabila nilai yang dirasakan pelanggan semakin tinggi, maka akan menciptakan kepuasan pelanggan yang maksimal.

Pengaruh Kualitas Pelayanan (Y1) terhadap Kepuasan Pelanggan (Y2), diperoleh koefisien struktural sebesar 0.661 dan P-value $<0.001$. Karena P-value $<0.05$, mengindikasikan bahwa adanya pengaruh signifikan antara Kualitas Pelayanan (Y1) terhadap Kepuasan Pelanggan (Y2). Artinya semakin tingginya Kualitas Pelayanan (Y1), akan mempengaruhi semakin tingginya Kepuasan Pelanggan (Y2). Dengan demikian, hipotesis 5 penelitian ini diterima. Hasil penelitian ini sesuai dengan pernyataan Kotler (2002) bahwa apabila kualitas layanan suatu jasa baik, maka pelanggan akan merasa puas. 
Hasil penelitian ini juga mendukung penelitian dari Beatrix Lapalelo, Riane Johnly Pio, dan Johny Revo Elia Tampi (2015) yang mendapatkan bahwa kualitas pelayanan berpengaruh positif terhadap kepuasan pelanggan.

\section{Kesimpulan}

Berdasarkan hasil analisis yang telah diuraikan pada bab sebelumnya, dalam penelitian ini dapat disimpulkan hal-hal berikut ini:

Terdapat pengaruh yang tidak signifikan dan positif antara Brand Image terhadap Kualitas Pelayanan. Dengan demikian, tinggi rendahnya Kualitas Pelayanan tidak dipengaruhi oleh Brand Image.

Terdapat pengaruh yang tidak signifikan dan negatif antara Brand Image terhadap Kepuasan Pelanggan. Dengan demikian, tinggi rendahnya Kepuasan Pelanggan tidak dipengaruhi oleh Brand Image. Ditemukan pula pengaruh tidak langsung yang tidak signifikan antara Brand Image terhadap Kepuasan Pelanggan melalui Kualitas Pelayanan.

Terdapat pengaruh yang tidak signifikan dan positif antara Persepsi Harga terhadap Kualitas Pelayanan. Dengan demikian, tinggi rendahnya Kualitas Pelayanan tidak dipengaruhi oleh Persepsi Harga.

Terdapat pengaruh yang signifikan dan positif antara Persepsi Harga terhadap Kepuasan Pelanggan. Dengan demikian, tinggi rendahnya Kepuasan Pelanggan dipengaruhi oleh Persepsi Harga.
Ditemukan pula pengaruh tidak langsung yang tidak signifikan antara Persepsi Harga terhadap Kepuasan Pelanggan melalui Kualitas Pelayanan.

Terdapat pengaruh yang signifikan dan positif antara Kualitas Pelayanan terhadap Kepuasan Pelanggan. Dengan demikian, tinggi rendahnya Kepuasan Pelanggan dipengaruhi oleh Kualitas Pelayanan.

\section{Saran}

Berdasarkan atas hasil penelitian dan masukan dari kepala cabang Datsun Nissan Martadinata, maka berikut beberapa saran yang dapat direkomendasikan:

\section{Perlunya ditingkatkan Brand Image} dari Datsun dengan cara mempromosikan Brand Image Datsun secara konsisten dan berkesinambungan, hal ini bisa memudahkan untuk mengingatkan, meningkatkan dan menjelaskan karakter kepada pelanggan yang sudah aware (mengetahui) apa yang mereka harapkan dengan menggunakan brand Datsun.

Harga mempengaruhi kualitas pelayanan karena pelanggan sensitif terhadap harga, sehingga dengan sedikit perubahan harga dapat mempengaruhi persepsi pelanggan terhadap kualitas pelayanan.

Mengevaluasi harga setiap periode waktu tertentu untuk menghindari harga produk yang lebih mahal, hal ini baik dilakukan agar Datsun bisa konsisten untuk memberikan kepuasan kepada setiap pelanggan. 
Kelima elemen dari kualitas pelayanan yaitu Keandalan, Jaminan, Bukti Fisik, Empati dan Daya Tanggap memiliki pengaruh yang signifikan secara bersamasama terhadap kepuasan pelanggan. Sehubungan dengan hal tersebut pihak Datsun perlu menjaga atau meningkatkan standar kualitas pelayanan yang telah ada dengan memperhatikan kelima aspek tersebut agar dapat menjaga atau bahkan meningkatkan tingkat kepuasan pelanggan.

Variabel kualitas pelayanan masih kurang digunakan sebagai variabel dependen, kebanyakan penelitian menggunakan kualitas pelayanan sebagai variabel independen. Meningkatkan penelitian dengan menggunakan kualitas pelayanan sebagai variabel independen baik adanya.

Penelitian ini belum meneliti aspek konversi approval leasing, karena hanya meliputi aspek brand image, persepsi harga, kualitas pelayanan dan kepuasan pelanggan. Maka untuk penelitian berikutnya bagi yang berminat meneliti di Datsun Nissan Martadinata dapat menggunakan aspek konversi approval leasing sebagai bahan penelitian.

\section{Daftar Pustaka}

Blumberg. 1999. Manfaat Pelayanan Terhadap Keputusan Menabung Nasabah Pada PT Bank Panin. Jakarta: Universitas Indonesia.

Ferdinand, A. 2002. Pengembangan Minat Beli Merek Ekstensi. Semarang: Universitas Diponegoro.
Gerson, R. F. 2002. Mengukur Kepuasan Pelanggan. Cetakan kedua, Jakarta: PPM.

Irawan, H. 2007. 10 Prinsip Kepuasan Konsumen. Jakarta: PT Elex Media Komputindo.

Keller, K. L. 2000. Strategic Brand Management: Building, Measuring, and Managing Brand Equity. New Jersey: Prentice Hall.

Kotler, P. 2000. Manajemen Pemasaran: Analisis, Perencanaan, Implementasi dan Control, Edisi kedelapan, Jilid I. Jakarta: Prenhallindo.

Kotler, P. and Armstrong, G. 2001. Dasardasar Pemasaran, Edisi Kedelapan. Jakarta: PT. Erlangga.

Kotler, P. and Keller, K. L. 2012. Manajemen Pemasaran. Edisi-12. Jakarta: Erlangga.

Lapalelo, B., Pio, R. J. and Tampi, J. R. E. 2015. Pengaruh Sistem Informasi Pemasaran dan Kualitas Pelayanan Terhadap Kepuasan Pelanggan dan Loyalitas Pelanggan. eJournal Unsrat JAP volume 1, nomor 28. Manado: Universitas Sam Ratulangi

Lovelock, C. and Wright, L. K. 2005. Manajemen Pemasaran Jasa. Jakarta: PT Indeks Kelompok Gramedia.

Marshall, R., Na, W. B., and Keller, K. L. 1999. Measuring brand power: Validating a model for optimizing brand equity". The Journal of Product and Brand Management. 8(3), 170184.

Paul, P. J. and Olson, J. C. 2000. Consumer Behaviour: Perilaku Konsumen dan Strategi Pemasaran, jilid 1 dan jilid 2. Jakarta: Erlangga. 
Setiadi, N. J. 2003. Perilaku Konsumen. Jakarta: Kencana.

Sugiarto, E. 2002. Psikologi Pelayanan dalam Industri Jasa. Jakarta: PT Gramedia Pustaka Utama.

Suwithi, N. W. 1999. Pelayanan Prima (Costumer Care). Makalah Penataran Guru Akomodasi Perhotelan Pada Pusat Pengembangan Penataran Guru Kejuruan; Jakarta.

Tjiptono, F. 2005. Brand Management and Strategy. Edisi-1. Yogyakarta: Andi.

Umar, H. 2005. Riset Pemasaran \& Perilaku Konsumen. Jakarta: PT Gramedia Pustaka Utama. 